South America by the Strasburg University some ten years ago, and spent some two years making a most thorough research in the geology of the continent, the tangible result being the remarkably complete map exbibited. His researches in South America prove that there is a most remarkable similarity between the geology of the two Americas, and especially between the geology of the southern United States and the southern continent.

The second paper was by Dr. August Rothpletz, of the University of Munich, Germany, on the Permian, Triassic, and Jurassic formations in the East Indian Archipelago. The doctor's paper was devoted to the description of some Mesozoic and Palæozoic fossils collected in two of the Indian islands by his friend Dr. Wichmann, during a geological exploration of the islands. Dr. Wichmann being geologist of the University of Utrecht, Holland, the collection; were of particular value, and Dr. Rothpletz's description and classification of them, to which he devoted his paper, was thorough and minute. He took occasion to ridicule some of the classifications of fossils which put them in one category when found in one place and in another when found somewhere else.

"Thermometamorphism in Igneous Rocks" was the title of the next paper presented. It was by Mr. Alfred Harker, of St. John's College, Cambridge, England, and dealt with the effects of high volcanic temperatures in the formation of rocks. He described the results of his researches in the lake region of England, where the volcanic forces of nature were particularly well marked.

Prof, Alexis Pavlow of the University of Moscow, Russia, presented a paper entitled "Sur les Couches Marines terminant le Jurassique et commençant le Crétace, et sur l'Histoire de leur Faune.'

Another paper, also in French, presented by Prof. Max Lohest, of the University of Liége, Belgium, was entitled "Sur l'Homme ccntemporain du Mammouth en Belgique." The contemporaneous existence of man was supported by prosfs additional to those heretofore given.

Baron Gerald de Geer, of Sweden, gave an interesting account of recent changes of level along the sea-board of the Scandinavian peninsula.

The most important new matter presented was a paper on "Foss.l Fishes of the Lower Silurian Rocks of Colorado," by Mr. C. D. Walcott, of the United States Geological Survey. The discovery of the fossil fish remains is of recent date, and attracts great attention among zoologists and geologists from its carrying back into the past, over a great time interval, our knowledge of vertebrate life. They are the oldest vertebrate remains known, and appear to be the ancestral types of the great ichthyic fauna of the classic "old red sandstone" of Europe, and the Devonian group of America.

In the discussion, Profs. Von Zittel, Jaekel, and F. Schmidt compared the fish remains exhibited with those of the Devonian, and stated that the Upper Silurian types were not represented in the fauna.

SECOND DAY.-From the committee appointed to draft appropriate resolutions relative to the death of Dr. Alexander Winchell, the President of the Society, Prof. Orton made a report which was adopted. The resolutions reported paid a just and touching tribute to the character of the deceased, and fittingly acknowledged the great services which he had rendered to the science in the course of the forty years of arduous and unremitting toil which he had devoted to its investigation. To his writings and lectures were attributed in a great degree the growing liberality and enlargement of thought of the more serious-minded portion of the community in regard to the theory of organic evolution as presented by Darwin and his successors. Dr. Winchell, the report affirmed, stated and defended with marked ability and courage and persuasive power this the most characteristic and far-reaching doctrine of modern geological science. "The first enunciation of this doctrine," the report stated, "was sure to a saken distrust and even bitter ho tility among a large class of people because of its apparent in compatibility $\mathrm{u}$ ith some of their most fundamental convictions and beliefs. To disregard the sincere apprehension of this great class, comprising, as it does, so much of the moral and intellectual force of the body politic, would be heartless. To mock at its fears, ill founded though they were, would be worse. What worthier service to science and the community than to disarm hostility by showing that the evolutionary philosophy, so far from degrading and dishonouring man, makes him in a peculiar sense the head and crown of the creation?"
In seconding the resolutions Dr. C. A. White paid a warm tribute to Dr. Winchell, with whom he had been on terms of intimacy for many years. As a further mark of respect the resolutions were adopted by a rising vote.

The first paper presented was by Dr. Frederick Schmidt, of St. Petersburg, Russia.

Prof. Gregoire Stefanescu, of the University of Bucharest, Roumania, presented "Sur l'Existence du Dinotherium ea Roumanie," the next paper. The Professor read it in French, illustrating it by drawings on the blackboard, and after he had finished, Prof. Dr. Charles Barrois read it over again in English, so that those who did not know French might not lose it. Though quite short the paper was very interesting. It brielly described a large number of bones of the Dinotherium found widely distributed over Roumania, which indisputably pointed to the existence of this almost unknown extinct animal in that land countless years ago. This was probably the largest mammal that ever inhabited the earth, its epoch being the Tertiary period. It had enormous tusks, that curved downward and backward in such a way that it could only hurt itself with them, and protably had a massive trunk. In character it more nearly resembled the elephant and rhinoceros of modern ages than any other known animal.

Prof. A. N. Krassnof, of the Charkow University, Russia, read the next paper on the black earth of the steppes of Southern Russia, its origin, distribution, and points of resemblance with the soils of the prairies of America. The paper traced the resemblance between the Russian steppes and the American prairies to their similar origin in the layers of the vegetables of years. Their remarkable fertility was touched on generally, and a technical account of the origin of the two plains was given.

\section{TECHNICAL CHEMISTRY.}

I $\mathrm{N}$ his Cantor Lectures on Photographic Chemistry, delive e.l last spring before the Society of Arts, and just issued by the Society in a separate form, Prof. Meldola opens with some remarks on the special position of technical training in chemistry, which should be carefully conisdered in connection with the present widespread movement in the direction of technical education throughout the country. He says :-

"There are many who identify technical instruction with the teaching of some handicraft, a notion which has no doubt arisen from the identification of technical skill with manual dexterity in some mechanical industry. By the adoption, either tacitly or openly, of this narrow definition, the chemical industries have suffered to a very large extent in this country, because their progress is more dependent on a knowledge of scientific principles, and much less dependent on manual dexterity than any of the other subjects dealt with in schemes of technical instruction. Now, in order to give technical instruction in a subject like photography, which is so intimately connected with chemistry, we may adopt one of two courses. The student may become a practical photographer in the first place, and may then be led on to the science of his practice by an appeal to the purely chemical principles brought into operation. This may be called the analytical method. The other method is to give the student a training in general chemistry first, and then to specialize his knowledge in the direction of photography. This may be regarded as a synthetical method.

"In other departments of technology, and especially in those where the underlying principles are of a mechanical nature, the analytical method may be, and has been, adopted with success. It is possib'e to lead an intelligent mechanic from his every.day occupations to a knowledge of the higher principles of mechanical science by making use of his experience of phenomena which are constantly coming under his notice. From this it is sometimes argued by those who are in the habit of regarding technical instruction f.om its jurely analytical side, that technical chemistry can be tau, ht by the same method. Some teachers may possibiy succeed in this process, but my own experience, both as a technologist and a teacher, has led me to the conclusion that, for chemical suljjects, the analytical method is both too cumbersome and circuitous to be of any real practical use. No person engaged in chemical industry in any capacity - whether workman, foreman, manager, or proprietor-can be taught the principles of chemical science out of his own industry, unless he has some considerable knowledge of

No. I I 47, VOL. 44] 
general principles to start with. No person who is not grounded in such broad principles can properly appreciate the explanation of the phenomena with which his daily experience brings him into contact, and if his previous training is insufficient to enable him to anderstand the nature of the changes which occur in the course of his operations, he cannot derive any advantage from technical instruction. These remarks will, I hope, serve to emphasize a distinction which exists between technical chemistry and uther technical subjects, and I have thought it desirable to avail myself of the present opportunity of calling particular attention to this point, because it is one which is generally ignored in all discussions on technical education.

"The reason for this difference in the mode of treatment of chemical subjects is not difficult to find. The chemical technologist - the man who is engaged in the manufacture of useful products out of certain raw materials-is, so far as the purely scientific principles are concerned, already at a very advanced stage, although he may not realize this to be the case. The chemistry of manufacturing operations, even when these are of an apparently simple kind, is of a very high order of complexity. There are many branches of chemical industry in which the nature of the chemical changes undergone by the materials is very imperfectly understood; there is no branch of chemical industry of which the pure science can be said to be thoroughly known. For these reasons I believe that I am justified in stating that the chemical technologist is working at a high level, so far as the science of his subject is concerned, and this explains why he cannot be dealt with by the analytical method.

"The general considerations which have been offered apply to the special subject of photography with full force. A person may become an adept as an operator without knowing anything of physics or chemistry; there are thousands of photographers all over the country who can manipulate a camera and develop and print pictures with admirable dexterity, who are in this position. If we adopt the narrow definition of technical instruction, ne should appoint such experts in our Colleges, and through them impart the art of taking pictures to thousands of others. But would our position as a photographing nation be improved by this process? I venture to think not. We might be carrying out the ideas of certain technical educators by adopting this method, but I do not imagine that in the long run the subject itself would be much advanced; our position in the scale of industry would not be materially raised by the wholesale manufacture of skilful operators. And so with all other branches of applied chemistry; it is technologists whose knowledge is based on a broad foundation that are wanted for the improvement of our industries. These are the men who are raised in the technical high schosls of the Continent, and whose training the Continental industries have had the wisdom to avail themselves of."

\section{AN ASTRONOMER'S WORK IN A MODERN OBSERVATOR Y.}

THE work of astronomical observatories has been divided into two classes, viz. astrometry and astrophysics. The first of these relates to astronomy of precision, that is to the determination of the positions of celestial objects; the second relates to the study of their physical features and chemical constitution.

Some years ago the aims and objects of these two classes of observatories might have been considered perfectly distinct, and, in fact, were so considered. But I hope to show that in more recent years their objects and their processes have become so interlaced that they cannot with advantage be divided, and a fully equipped modern observatory must be understood to include the work both of astrometry and astrophysics.

In any such observatory the principal and the fundamental instrument is the transit circle. It is upon the position in the heavens of celestial objects, as determined with this instrument or with kindred instruments, that the whole fair superstructure of exact astronomy rests ; that is to say, all that we find of information and prediction in our nautical almanacs, all that we know of the past and can predict of the future motions of the celestial bodies.

I Friday Evening Discourse delivered at the Royal Institution by Dr. David Gill, F.R.S., Her Majesty's Astronomer at the Cape of Good Hope, on May 29, r8gr.

NO. I I 47, VOL. 44]
Hese is a vely small and imperfect model, but it will serve to render intelligible the photograph of the actual instrument which will be subsequently projected on the screen. [Here the lecturer described the adjustments and mode of using a transit circle.]

W'e are now in a position to understand fhotographs of the instrument itself. Bul first of all as to the house in which it duells. Here, now on the screen, is the outside of the main building of the Royal Observatory, Cape of Good Hope. I select it simply because, being the observatory which it is my privilege to direct, it is the one of which I can most easily procure a series of photographs. It was built during the years I 824-28, and like all the observatories built about that time, and jike too many built since, it is a very fair type of most of the things which an observatory should not be. It is, as you see, an admirably solid and substantial structure, innocent of any architectural charm, and so far as it affords an excellent $\mathrm{d}$ w elling-place, good library accommodation, and good rooms for computers, no fault can be found with it. But these very qualities render it undesirable as an observatory. An essential matter for a perfect observatory should be the posssibility to equalize the internal and the external temperature. The site of an instrument should also be free from the immediate surroundings of chimneys or other origin of ascending currents of heated air. Both these conditions are incompatible with thick walls of masonry and the chimneys of attached dwelling houses, and therefore, as far as possible, I have removed the instruments to small detached houses of their own. But the transit circle still remains in the main building, for, as will be evident to you, it is no easy matter to transport such an instrument.

The two first photographs show the instrument, in one case pointed nearly horizontally to the north, the other pointed nearly vertical. Neither can show all parts of the instrument, but you can see the massive stone piers, weighing many tons each, which, resting on the solid blocks 10 feet below, support the pivots. Here are the counter-weights which remove a great part of the weight of the instrument from the pivots, leaving only a residual pressure sufficient to $\epsilon$ nable the pivots to preserve the motion of the instrument in its proper plane. Here are the microscopes by which the circle is read. Here the opening through which the instrument views the meridian sky. The observer's chair is shown in this diagram. His work appears to be very simple, and so it is, but it requires special natural gifts, patience and devotion, and a high sense of the importance of his work to make a first-rate meridian observer. Nothing apparently more monotonous can be well imagined if a man is "not to the manner born."

Having directed his instrument by means of the setling circle to the required altitude, he clamps it there and waits for the star which he is about to observe to enter the field. This is what he sees. [Artificial transit of a star by lantern.]

As the star enters the field it passes wire after wire, and as it passes each wire he presses the key of his chronograph and records the instant automatically. As the star passes the middle wire he bisects it with the horizontal web, and again similarly records on his chronograph the transit of the star over the remaining webs. Then he reads off the microscopes by which the circle is read, and also the barometer and thermometer, in order afterwards to be able to calculate accurately the effect of atmospheric refraction on the observed altitude of the star; and then his observation is finished. Thus the work of the meridian observer goes on, star after star, hour after hour, and night after night ; and, as you see, it differs very widely from the popular notion of an astronomer's occupation. It presents. no dreamy contemplation, no watching for new stars, no unexpected or startling phenomena. On the contrary, there is beside him the carefully prepared observing-list for the night, the previously calculated circle setting for each star, allowing just sufficient time for the new setting for the real star after the readings of the circle for the previous observation.

After four or five hours of this work, the observers have had enough of it ; they have, perhaps, observed fifty or sixty stars, they determine certain instrumental errors, and betake themselves to bed, tired, but (if they are of the right stuff) happy and contented men. At the Cape we employ two observersone to read the circle, and one to record the transit. Four obselvers are empluyed, and they are thus on duty each alternate night. Such is the work that an outsider would see nere he to enter a working meridian observatory at night, but he 